\title{
O gênero Galeandra (Orchidaceae: Catasetinae) no estado do Paraná, Brasil
}

\author{
The genus Galeandra (Orchidaceae: Catasetinae) in the Paraná state, Brazil
}

Thuane Bochorny ${ }^{1,3}$, Silvana Helena Nascimento Monteiro ${ }^{2}$ \& Eric de Camargo Smidt ${ }^{1}$

\begin{abstract}
Resumo
Galeandra possui 18 espécies terrícolas e epífitas com distribuição neotropical, sendo reconhecidas principalmente pelas flores com labelo em forma de funil e calcar na base. O objetivo deste trabalho foi realizar o estudo taxonômico de Galeandra no estado do Paraná, apresentando descrições, ilustrações, mapa de distribuição, chave de identificação, status de conservação e comentários para cada espécie. O gênero está presente nas cinco unidades fitogeográficas do estado, ocorrendo em Floresta Estacional Semidecidual ( $G$. beyrichii e $G$, styllomisantha), nas Florestas Ombrófilas Mista e Densa (G. beyrichii) em vegetações de campo e áreas relictuais de Cerrado (G. beyrichii, G. montana e G. paraguayensis, sendo G. montana o primeiro registro para o estado). De acordo com os critérios da IUCN, G. beyrichii apresenta baixo risco (LC) de extinção, G. paraguayensis pode ser considerada em perigo (EN) e G. montana e G. styllomisantha como criticamente em perigo (CR) sendo a última possivelmente extinta no estado.
\end{abstract}

Palavras-chave: Biodiversidade, Flora do Paraná, IUCN, Floresta Atlântica.

\begin{abstract}
Galeandra has 18 species with Neotropical distribution. Consisting of terrestrial and epiphytic species, the genus is recognized by flowers with funnel-shaped lip and spur at the base. The aim of this study was to do a taxonomic treatment of Galeandra in Paraná state, with descriptions, illustrations, distribution maps, identification key, conservation status and comments on each species. The genus is present in the five phytogeographic regions of the Paraná. In Semideciduous Forest there are two species (G. beyrichii and Galeandra styllomisantha), in Atlantic rainforest and Araucaria forest one species (G. beyrichii), and in steppe vegetation and in relictual areas of savanna three species (G. beyrichii, G. montana and G. paraguayensis), with G. montana being the first record for the state. According to IUCN criteria, G. beyrichii has low extinction risk (LC), G. paraguayensis is endangered (EN), and G. montana and G. styllomisantha are critically endangered (CR). In fact, G. styllomisantha is possibly extinct locally.

Key words: Biodiversity, Paraná flora, IUCN, Atlantic rainforest.
\end{abstract}

\section{Introdução}

Galeandra Lindl., um dos gêneros da família Orchidaceae, subfamília Epidendroideae, é composto por 18 espécies terrícolas e epífitas, sendo reconhecidas principalmente pelas flores com labelo em forma de funil e calcar na base (Monteiro et al. 2010). Este gênero possui distribuição neotropical, sendo que 14 espécies ocorrem no Brasil (Dressler 1993; Pridgeon et al., 2009; Monteiro et al. 2010).
Entre os principais estudos de Galeandra podem ser citados Barbosa-Rodrigues (1882) que propôs a primeira classificação infragenérica, Cogniaux (1895) na Flora Brasiliensis revisou as espécies brasileiras conhecidas e Pabst \& Dungs (1975) que listaram 15 espécies em Orchidaceae Brasiliensis. Monteiro (2007) realizou a revisão para o gênero e recentemente Monteiro et al. (2009; 2010) realizaram a revisão das espécies para a Amazônia e a filogenia do gênero.

\footnotetext{
${ }^{1}$ Universidade Federal do Paraná, Depto. Ciências Biológicas, Centro Politécnico, Jardim da Américas, C.P. 19031, 81531-980, Curitiba, PR, Brasil

${ }^{2}$ Instituto de Pesquisas Jardim Botânico do Rio de Janeiro, Herbário, R. Pacheco Leão, 915, Horto, 22460-030, Rio de Janeiro, RJ, Brasil.

${ }^{3}$ Autor para correspondência: tbochorny@gmail.com
} 
A Região Sul do Brasil pode ser considerada limítrofe para o gênero, com ocorrência apenas de G. beyrichii Rchb. f. para os estados do Rio Grande do Sul e Santa Catarina (Barros et al. 2014). No Paraná estão presentes, G. beyrichii, G. paraguayensis Cogn. e G. styllomisantha (Vell.) Hoehne (Ziller \& Hatschbach, 1995; Barros et al. 2014), todas de hábito terrícola.

O objetivo deste trabalho foi apresentar o primeiro estudo taxonômico de Galeandra para o estado, através de chave de identificação, descrições, mapa de distribuição, ilustrações, status de conservação e comentários para as espécies, contribuindo para o projeto Flora do Paraná.

\section{Material e Métodos}

Foram estudadas as coleções dos herbários AMES, EFC, HBR, HUEPG, IBT, MBM, NY, P, $\mathrm{R}, \mathrm{RB}, \mathrm{SP}, \mathrm{SPF}$ e UPCB (siglas segundo Thiers [continuously updated]). O material coletado durante as expedições de campo (março de 2013 a março de 2014) seguiu procedimento de herborização de Fidalgo \& Bononi (1989) e encontram-se depositados no herbário UPCB.

A partir dos dados morfológicos qualitativos e quantitativos obtidos, as descrições foram elaboradas seguindo a terminologia usual de Stearn (2004) e Gonçalves \& Lorenzi (2011). Os comentários de cada espécie foram baseados nas informações das exsicatas analisadas e em dados complementares de Monteiro et al. (2009, 2010). Os sinônimos aceitos neste trabalho estão de acordo com Monteiro et al. (2010). A distribuição geográfica dos táxons no estado do Paraná foi mapeada em imagem delimitada por quadrículas de $1^{\circ} \times 1^{\circ}$ através do programa DIVA-GIS 7.5 (Hijmans et al. 2012). O status de conservação das espécies foi inferido para o estado do Paraná, seguindo as recomendações do sistema IUCN (2014) levando em consideração o número de localidades, área, extensão e qualidade do habitat, sendo também examinada a Lista Vermelha de Plantas Ameaçadas de Extinção no Estado do Paraná (Hatschbach \& Ziller 1995).

A descrição dos habitats ocupados pelas espécies foi baseada nas cinco regiões naturais reconhecidas para o estado por Maack (1968): Litoral, Serra do Mar, Primeiro, Segundo e Terceiro Planaltos, apresentando cinco tipos de vegetação (Roderjan et al. 2002; IBGE 2012): Floresta Ombrófila Densa; Floresta Ombrófila Mista; Estepe (campos); Floresta Estacional Semidecidual e Savana (Cerrado).

\section{Resultados e Discussão}

Foram analisadas 35 exsicatas, referentes às coletas realizadas em 19 municípios, sendo encontradas quatro espécies terrícolas em todo o estado (Fig. 2). Nas vegetações de campo e áreas relictuais de Cerrado ocorrem três espécies (G. beyrichii, G. montana e G. paraguayensis), especialmente na região do Planalto Ponta Grossa, limitado pela presença da Escarpa Devoniana. $\mathrm{Na}$ Floresta Estacional Semidecidual ocorrem duas espécies (G. beyrichii e G. styllomisantha), nas Florestas Ombrófilas Mista e Densa apenas uma ( $G$. beyrichii). O registro de $G$, junceaoides Barb. Rodr. para o Paraná (Barros et al. 2014) é um equívoco, pois a coleta em questão trata-se de G. styllomisantha, que possui grande semelhança morfológica devido ao labelo rômbico e trilobado de margem crenulada.

Na lista vermelha de plantas ameaçadas de extinção no estado do Paraná (Hatschbach \& Ziller 1995) G. paraguayensis e G. styllomisantha aparecem na categoria em perigo. O presente estudo confirma os poucos registros destas espécies no Paraná, e inclui G. montana e $G$. styllomisantha como criticamente em perigo, segundo os critérios da IUCN (2014).

Galeandra Lindl., Illustr. Orch. Pl. Gen. T. 8. 1832.0

$=$ Corydandra Rchb. Deut. Bot. Herb.-Buch 53 . 1841.

Ervas terrícolas. Raízes cilíndricas, fasciculadas. Pseudobulbos subterrâneos, alvacentos, ovoides, recobertos por bainhas foliares. Bainhas foliares persistentes, imbricadas sobre o pseudobulbo. Folhas laterais, dísticas, coriáceas, lineares, glabras com ápice agudo, raro ausentes (plantas áfilas). Inflorescência em racemo simples ou composto, ereta, pauci à pluriflora; pedúnculo cilíndrico, recoberto por brácteas amplectivas, acuminadas; brácteas florais semelhantes às do pedúnculo. Pedicelo, incluindo o ovário, ereto, com uma bráctea na base. Flores membranáceas; sépalas e pétalas livres, eretas a reflexas, agudas, margens inteiras; sépala dorsal, oblongo-lanceolada; sépalas laterais levemente falcadas; pétalas semelhantes à sépala dorsal, ligeiramente mais largas; labelo infundibuliforme, trilobado, rômbico ou rômbico-obovado, pubérulo a pubescente, ápice retuso à acuminado; disco composto por quatro carenas paralelas; calcar linear ou obtuso, levemente descendente; coluna apiculada, ligeiramente encurvada, glabra ou pubérula, cavidade do estigma com alas laterais; antera bilocular, cuculada, subarredondada, com ápice obtuso; polínias, duas, ovoides, livres. Fruto cápsula, oblongo, tricarpelar; sementes numerosas. 
Chave para as espécies de Galeandra (Orchidaceae) ocorrentes no estado do Paraná:

1. Folhas estreitamente lineares, $2-5 \mathrm{~cm}$ larg.; calcar filiforme.

2. Flores com sépalas e pétalas esverdeadas, rajadas de violeta, labelo esverdeado com listras alvorosadas a vináceas nos lobos, margem inteira ou algo crenada, ápice acuminado

Galeandra paraguayensis

2'. Flores com sépalas e pétalas lilás-claro, labelo lilás-claro com listras vináceas tênues, margem crenulada, ápice emarginado. Galeandra styllomisantha

1'. Folhas lineares 6-8 cm larg. ou ausentes; calcar saquiforme.

3. Plantas áfilas; inflorescência em racemo simples; labelo inconspicuamente trilobado, brancoesverdeado com estrias vináceas nos lobos, tricomas pubescentes ..... Galeandra beyrichii

3'. Plantas com folhas persistentes; inflorescência em racemo simples ou composto; labelo conspicuamente trilobado, branco-amarelado a branco-rosado, lobo mediano vináceo, tricomas pubérulos.

Galeandra montana

1. Galeandra beyrichii Rchb. f., Linnaea, 22: 854. 1849

= Galeandra viridis Barb. Rodr., Revista Engen. 3(9): 143. 1881.

= Galeandra coxinnensis Hoehne, Relat. Commiss. Linhas. Telegr. Estratég. Mato Grosso Amazonas. 4: $15,1951$.

$=$ Galeandra fiebrigii Schltr., Repert. Sp. Nov. Regni Veg. 10: 47. 1922.

Fig. 1a-d

Erva terrícola. Pseudobulbo 1,6-3,4 × 1,1$2,1 \mathrm{~cm}$. Folhas ausentes. Inflorescência racemosa, 2-18 flores; pedúnculo 21-85 cm compr.; brácteas do pedúnculo 2,9-7,4 $\mathrm{cm}$ compr.; bráctea floral 8-14 mm compr. Flores com calcar 21-38 mm compr.; sépalas esverdeadas, reflexas; sépala dorsal $17-29 \times 2-6 \mathrm{~mm}$; sépalas laterais $18-29 \times 3-6,6$ $\mathrm{mm}$; pétalas esverdeadas, eretas, $18-28 \times 3-6,8$ $\mathrm{mm}$; labelo 16-23 × 18-30 mm, rômbico-obovado, inconspicuamente trilobado, alvo com nervuras internas esverdeadas e listras vináceas nas margens, ápice retuso, margem crenada, pubescente na porção central; calcar 5-6× 1,5-3 mm, saquiforme; coluna 6-9 × 1,2-2,6 mm, pubérula; antera ca. 1,8 $\times 2,5 \mathrm{~mm}$. Frutos ca. $3 \times 1,6 \mathrm{~cm}$.

Material examinado: Campina Grande do Sul: Ribeirão Grande, 19.III.1967, fl. e fr., G. Hatschbach 16195 (HB, MBM), Ribeirão Grande, 6.II.1968 G. Hatschbach 18544 (MBM). Carambeí: Catanduva de Fora, 27.XII.2010, fl., M.E. Engels 229 (HUPG), Catanduva de Fora, 8.I.2011, fl., M.E. Engels 232 (HUPG). Cerro Azul: Morro Grande, 5.II.1950, fl., G. Hatschbach (MBM 49645), Morro Grande, 25.I.1974, fl., G. Hatschbach, 33761 (HB, MBM). Cornélio Procópio: arredores, 20.III.2009, fl., J.M. Silva \& E.M. Cunha 7151 (MBM). Curitiba: Ahú, Rua Estados Unidos, s/d, fl., F. Marino Neto 26 (MBM). Diamante do Norte: 27.IV.1989, fl., Y.S. Kuniyoshi \& C.V. Roderjan 5333 (EFC). Foz do
Iguaçu: Parque Nacional de Foz do Iguaçu, 19.II.1968, fl., G. Hatschbach (MBM 49647). Irati: Vila São João, 31.III.1983, fl., R. Kummrow \& L. Bohs 2265 (MBM). Jaguariaíva: Casa Nova in silva primaeva, 4.IV.1915, fl., Dusen 16999 (AMES). Mandirituba: Quatro Pinheiros, 25.I.1968, fl., G. Hatschbach 18436 (MBM), Rio do Maurício, 18.I.1970, fl., G. Hatschbach 25981 (MBM). Ponta Grossa: Fortaleza, 13.XII.1969, fl., G. Hatschbach, 23222 (MBM). Piraí do Sul: Flona de Piraí do Sul, 11.I.2011, fl., M.E. Engels 228 (HUPG). Rio Branco do Sul: Santa Cruz, 24.III.1971, fl., G. Hatschbach 26588 (MBM). Santa Maria do Oeste: Rodovia Pitanga-Santa Maria do Oeste, próximo do Rio Feio, 19.II.2004, fl., G. Hatschbach 76863 (MBM). Siqueira Campos: arredores de Siqueira Campos, 29.III.1974, fl., R. Kummrow 483 (MBM). Tibagi: Fazenda Monte Alegre, Harmonia, 21.II.1953, fl. e fr., G. Hatschbach (MBM 49646), Parque Estadual do Guartelá, 20.I.2004, fl., M.R.B. do Carmo 658 (HUPG).

Galeandra beyrichii ocorre desde o sul da Flórida, México, América Central, Venezuela, Colômbia, Peru, Bolívia, Paraguai e Argentina (Govaerts 2014). No Brasil ocorre nos estados da BA, DF, ES, GO, MT, MG, SP, RJ, PR, SC e RS (Barros et al. 2014). No Paraná está presente na vegetação de Florestas Ombrófilas Densa e Mista, Estepe, Cerrado e Floresta Estacional Semidecidual, em áreas sombreadas de subosque. Floresce entre os meses de dezembro a abril.

Galeandra beyrichii distingui-se das demais espécies por não possuir folhas, sendo uma espécie provavelmente saprófita (Pridgeon et al. 2009). Possui inflorescência em racemo simples e labelo alvo com nervuras internas esverdeadas e estrias vináceas nos lobos. De acordo com os critérios da IUCN (2014) enquadra-se na categoria não ameaçada (LC), pois a espécie está presente em 15 municípios do estado, ocorrendo em grande número de localidades. 


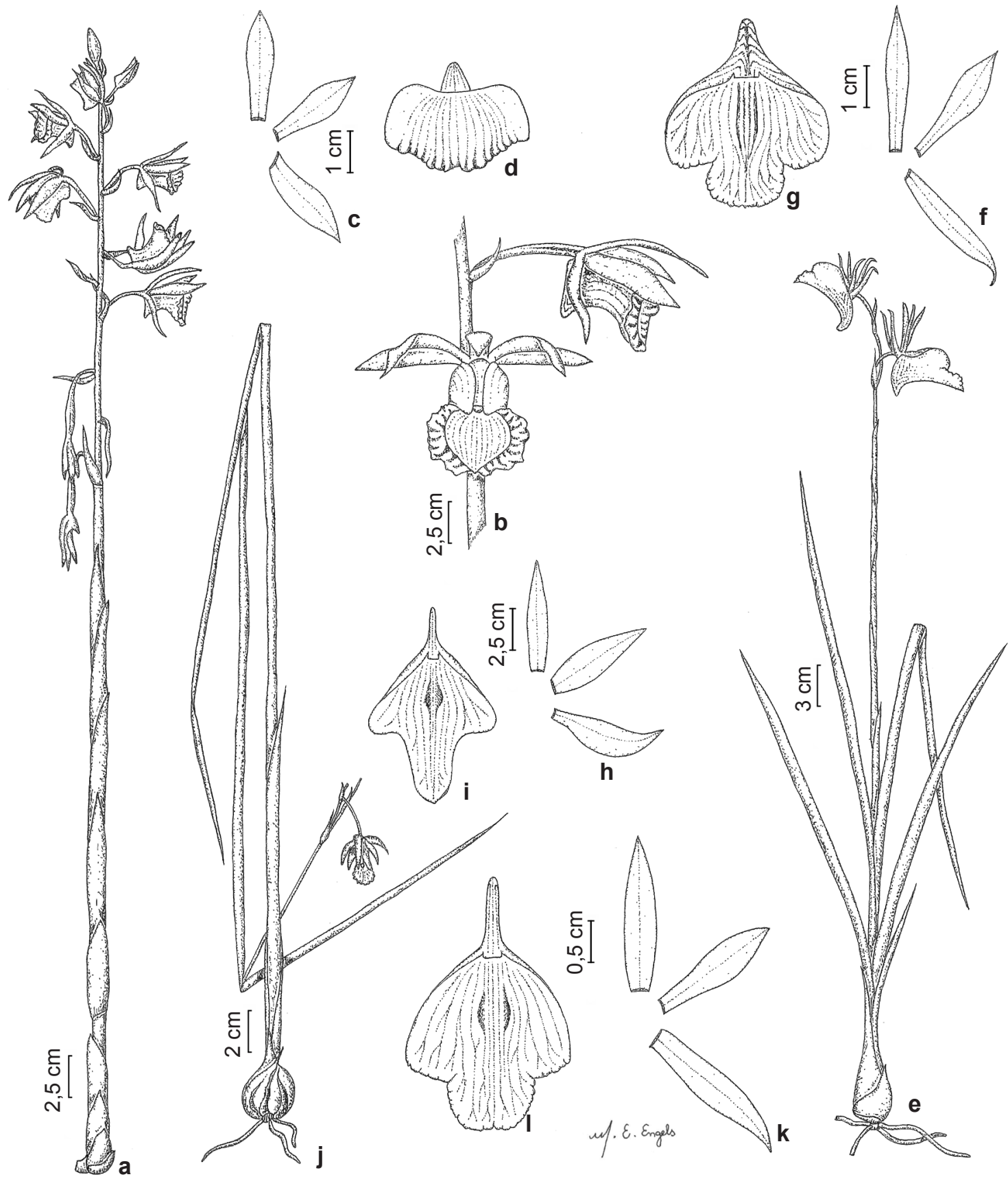

Figura 1 - a-d. G. beyrichii - a. Hábito, destacando a disposição das brácteas; b. Flor, vista frontal e lateral; c. Sépalas e pétalas; d. Labelo em forma de funil. e-g. G. montana - e. Hábito, destacando disposição das folhas; f. Sépalas e pétalas; g. Labelo trilobado. h-i. G. paraguayensis - h. Sépalas e pétalas; i. Labelo trilobado. j-1. G. styllomisantha - j. Hábito, destacando disposição das folhas e inflorescência; k. Sépalas e pétalas; 1. Labelo trilobado. (a: Silva et al. 2873; b, c e d: Engels 229; e, f e g: T. Bochorny \& M. Engels 122, Hatschbach 23753; h e i: Cervi et al. 6204; j, k e 1: Hatschbach 15891).

Figure 1 - a-d. G. beyrichii - a. Habit, emphasizing bracts arrangement; b. Flower, front and lateral view; c. Sepals and petals; d. Funnelshaped lip. e-g. G. montana - e. Habit, emphasizing bracts arrangement; f. Sepals and petals; g. Lobed lip. h-i. G. paraguayensis - h. Sepals and petals; i. Lobed lip, j-1. G. styllomisantha-j. Habit, emphasizing bracts arrangement and inflorescence; k. Sepals and petals; 1. Lobed lip. (a: Silva et al. 2873; b, c e d: Engels 229; e, f e g: T. Bochorny \& M. Engels 122, Hatschbach 23753; h e i: Cervi et al. 6204; j, k e l: Hatschbach 15891). 
2. Galeandra montana Barb. Rodr. Revista Engen. 3(5): 73. 1881. Fig. 1e-g Pseudobulbo 2,8-4×1,9-2,1 cm. Folhas 48$50 \times 6-8 \mathrm{~cm}$, lineares. Inflorescência em racemo simples ou composto, 3-5 flores; pedúnculo 30-69 cm compr.; brácteas do pedúnculo 5,5-12 cm compr.; bráctea floral ca. $7 \mathrm{~mm}$ compr. Flores ca. $38 \mathrm{~mm}$ compr; sépalas castanhoavermelhadas ou verde-claras mescladas com castanho, eretas ou reflexas; sépala dorsal ca. 22 $\times 4 \mathrm{~mm}$; sépalas laterais ca. $21 \times 2 \mathrm{~mm}$; pétalas ca. $21 \times 4 \mathrm{~mm}$, eretas; labelo ca. $14-15 \times 21 \mathrm{~mm}$, rômbico-obovado, conspicuamente trilobado, alvo-amarelado a alvo-rosado, lobos violáceos, ápice obtuso, margem crenada, pubérulo na porção central; calcar ca. $7 \times 0,8-1,6 \mathrm{~mm}$, saquiforme; coluna ca. $15 \times 3 \mathrm{~mm}$, glabra; antera ca. 2,1 × 2,4 mm. Fruto ca. $3 \times 1,2 \mathrm{~cm}$.

Material examinado: Tibagi: Parque Estadual do Guartelá, 6.VII.2013, fr., T. Bochorny \& M. Engels 122 (UPCB).

Material adicional examinado: MATO GROSSO: Aquidauana, Serra Maracaju, 17.II.1970, fl., G. Hatschbach 23753 (MBM).

Galeandra montana é endêmica do Brasil e ocorre nos estados de RO, PA, TO, RN, SE, MA, BA, DF, GO, MT, MS, MG e SP (Barros et al. 2014). Este estudo apresenta o primeiro registro da espécie para o estado do Paraná, na localidade do Parque Estadual do Guartelá, ampliando o limite de distribuição para o sul do Brasil. Floresce entre os meses de dezembro a julho em áreas de campo.

Galeandra montana diferencia-se das demais espécies por possuir flores maiores, labelo brancoamarelado a branco-rosado com lobos vináceos, calcar saquiforme e folhas lineares largas e persistentes. $\mathrm{O}$ espécime foi identificado através dos resquícios de perianto presentes no fruto. Segundo os critérios da IUCN (2014) enquadra-se na categoria criticamente em perigo $(\mathrm{CR})$, pois possui apenas um registro em todo o estado do Paraná.

3. Galeandra paraguayensis Cogn., Bull. Herb. Boissier. ser. 2,3:933. 1903.

= Galeandra paranaensis Schltr., Repert. Sp. Nov. Regni Veg. 16: 331. 1920.

Fig. 1h-i

Pseudobulbo 2-2,1 × 1,5-2,1 cm. Folhas 24$33 \times 2-5 \mathrm{~cm}$, estreitamente lineares. Inflorescência racemo simples ou composto, 2-4 flores; pedúnculo 15-37 cm compr.; brácteas do pedúnculo 3,2-6,5 cm compr.; bráctea floral 4-12 mm compr. Flores com calcar 25-29 mm compr.; sépalas esverdeadas, rajadas de violeta, ligeiramente reflexas; sépala dorsal 19-25 × 4-7 mm; sépalas laterais 19-23 $\times 5-7 \mathrm{~mm}$; pétalas esverdeadas, rajadas de violeta, recurvadas no ápice, $18-23 \times 5-7 \mathrm{~mm}$; labelo 23-31 × 17-22 mm, rômbico, trilobado, esverdeado com listras vináceas nos lobos laterais e branco-rosado no lobo mediano, ápice longamente acuminado, margem inteira ou algo crenada, levemente pubescente na porção central; calcar 7-9 $\times 0,5-0,6 \mathrm{~mm}$, filiforme; coluna $8-10 \times 0,8-1,5$ $\mathrm{mm}$, pubérula; antera 1,6-2 × 1,8-2,2 mm. Frutos ausentes.

Material examinado: Balsa Nova: Recanto dos Papagaios, 28.X.2006, fl., E. Barbosa \& E.M. Cunha 1792 (MBM). Palmeira: Rio Capivara, 10.XII.1966, fl., G. Hatschbach (MBM 49648), Rio dos Papagaios, 1.XII.1999, fl., E.P. Santos (MBM), Rio dos Papagaios, 10.VIII.2000, fl., E.P. Santos 852 (IBT, UPCB), km 60 da rodovia Curitiba-Ponta Grossa, 8.XII.1965, fl., Leining 359 (HB). Ponta Grossa: Recanto dos Papagaios, 20.XI.1996, fl., A.C. Cervi et al. 6204 (MBM).

Galeandra paraguayensis ocorre na Bolívia, Paraguai (Govaerts 2014) e no Brasil (MT, GO, DF, SP e PR) (Barros et al. 2014). Ocorre no Paraná nas vegetações de campo. Floresce entre os meses de agosto a dezembro em margens de córregos e campos úmidos.

Galeandra paraguayensis assemelha-se muito a $G$. styllomisantha em estado vegetativo por possuírem folhas lineares estreitas. Diferenciase por apresentar labelo com ápice acuminado, sépalas e pétalas esverdeadas rajadas de violeta. De acordo com os critérios da IUCN (2014) esta espécie enquadra-se na categoria em perigo (EN), pois possui registro de ocorrência em apenas três localidades do estado do Paraná.

4. Galeandra styllomisantha (Vell.) Hoehne Arq. Bot. Estado São Paulo. II: 146. 1952.

三Orchis styllomisantha Vell., Fl. Flum. 9:t. 46. 189. 1831.

= Galeandra juncea Lindl., Sert. Orchid. Sub. I. 37. 1840 .

Fig. $1 \mathrm{j}-1$

Pseudobulbo ca. 1,6 × 2,0 cm. Folhas 23-37 $\times 2-5 \mathrm{~cm}$, estreitamente lineares. Inflorescência racemo simples ou composto, 1-2 flores; pedúnculo 27-37 cm compr.; brácteas do pedúnculo 6,4-7,1 cm compr.; bráctea floral 3-7 mm compr. Flores com calcar 21-24 mm compr.; sépalas lilás claro, ligeiramente reflexas; sépala dorsal 15-17 × 2-3 $\mathrm{mm}$; sépalas laterais $12-13 \times 2-3,2 \mathrm{~mm}$; pétalas 


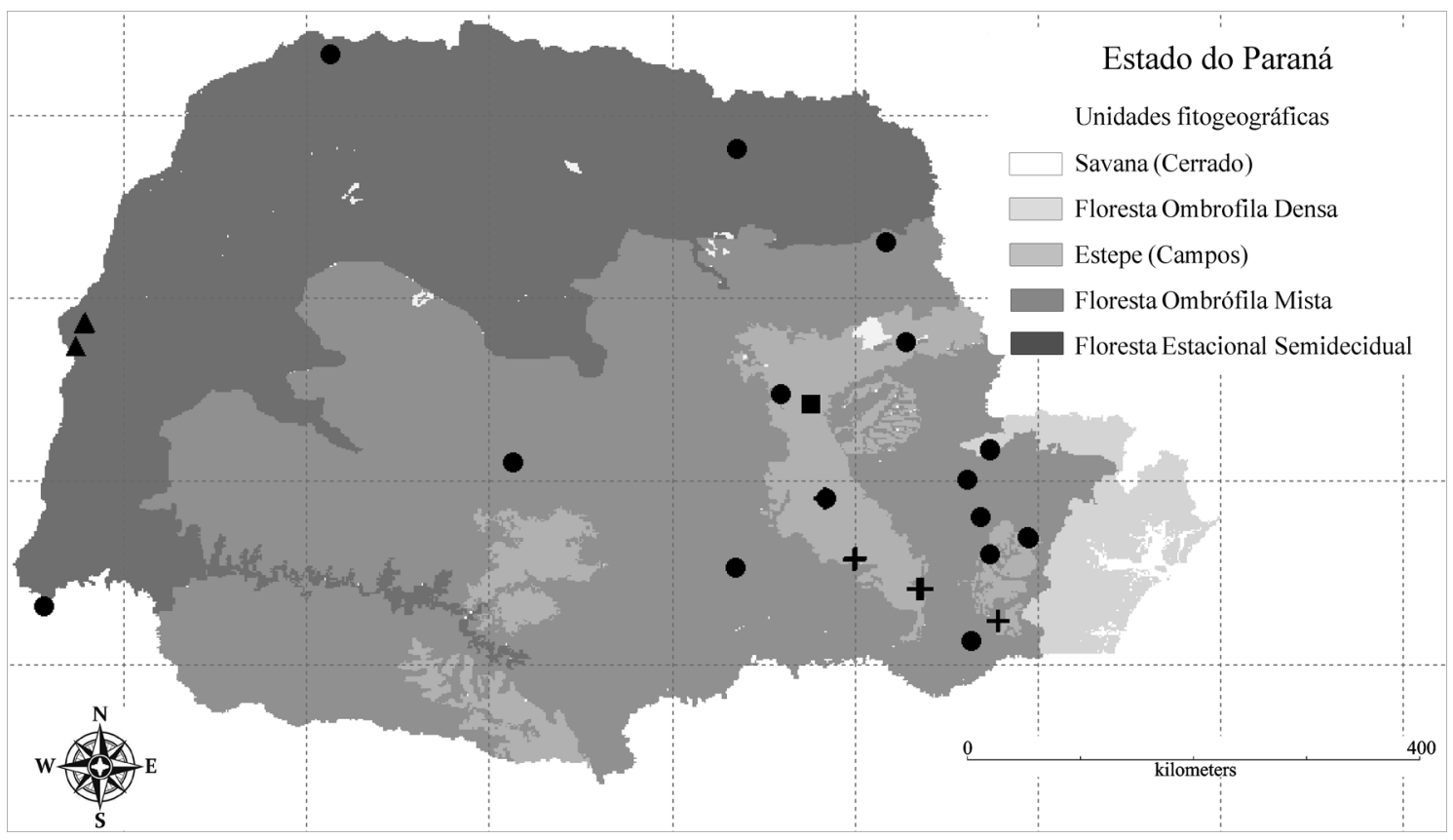

Figura 2 - Mapa da distribuição geográfica de Galeandra no estado do Paraná: (•) G. beyrichii; ( $\mathbf{\Delta}$ ) G. styllomisantha; (+) G. paraguayensis; (ロ) G.montana).

Figure 2 - Geographic distribution map of Galeandra in Paraná state: $(\bullet)$ G. beyrichii; ( $\mathbf{\Delta})$ G. styllomisantha; (+) G. paraguayensis; (घ) G.montana).

lilás-claro, eretas, 14-15 × 2-2,1 mm; labelo 14-15 $\times 21 \mathrm{~mm}$, rômbico, trilobado, lilás claro com listras vináceas tênues, ápice emarginado, margem crenulada, levemente pubescente na porção central; calcar ca. $7 \times 0,8-1,6 \mathrm{~mm}$, filiforme; coluna ca. 7 $\times 1,1 \mathrm{~mm}$, glabra; antera ca. $1,5 \times 2,2 \mathrm{~mm}$. Frutos ausentes.

Material examinado: Guaíra: Sete Quedas, 13.XI.1963, fl., E. Pereira \& G. Hatschbach 7871 (NY, HB e MBM), 24.I.1967, fl., G. Hatschbach 15891 (MBM, UPCB), 7.IX.1979, fl., Buttura 296 (MBM).

Galeandra styllomisantha ocorre no Panamá, Venezuela, Colômbia, Bolívia, Peru, Guiana, Suriname, Guiana Francesa (Govaerts 2014) e Brasil (BA, GO, TO, DF, MT, MS, AP, PA, RO, MG, AC, MA, RJ, SP e PR) (Barros et al. 2014). Ocorre no Paraná na vegetação de Floresta Estacional Semidecidual. Floresce entre os meses de setembro a janeiro, cresce em locais de campo limpo com solo arenoso úmido.

Galeandra styllomisantha assemelha-se vegetativamente a $G$. paraguayensis, porém diferencia-se pelas flores com labelo de ápice emarginado, e pétalas e sépalas da mesma cor do labelo. Segundo os critérios da IUCN (2014), se enquadra na categoria criticamente em perigo (CR), pois possui registro em apenas uma localidade no estado do Paraná, no município de Guaíra. O último registro da espécie aconteceu em 1979, há 35 anos, na localidade de Sete Quedas (local atualmente inundado pela Usina Hidrelétrica de Itaipu) estando possivelmente extinta no estado.

\section{Agradecimentos}

Aos curadores dos herbários, o empréstimo dos materiais e a Mathias Erich Engels, a confecção das ilustrações. À CAPES-PNADB (998/2010 Proposta 125 botânica UFPR/IBT/Unicamp), a bolsa de Mestrado concedida, ao IAP e ao ICMBio, as autorizações de coletas e a bolsa de Produtividade em Pesquisa do CNPq - Nível 2 para ECS. Agradecemos também as sugestões dos dois revisores por tornarem o texto mais claro e padronizado.

\section{Referências}

Barbosa-Rodrigues, J. 1882. Genera et Species Orchidearum Novarum, Vol. 2. Tipografia Nacional, Rio de Janeiro. 163p.

Barros, F.; Vinhos, F.; Rodrigues, V.T.; Barberena, F.F.V.A.; Fraga, C.N.; Pessoa, E.M.; Forster, W.; Menini Neto, L.; Furtado, S.G.; Nardy, C.; Azevedo, C.O. \& Guimarães, L.R.S. 
2014. Orchidaceae. In: Lista de Espécies da Flora do Brasil. Jardim Botânico do Rio de Janeiro. Disponível em <http:/www.floradobrasil.jbrj.gov. br/jabot/floradobrasil/FB11597>. Acesso em 25 novembro 2014

Cogniaux, C.A. 1895. Orchidaceae: Galeandra. In: Martius, C.F.P.; Eichler, A.G. \& Urban, I. (eds.). K.F.P. von. Flora Brasiliensis. Frid. Fleischer, Lipsae, Munchen. Vol. 3, pars 4, pp. 293-310.

Dressler, R.L. 1993. Phylogeny and classification of the orchid family. Dioscorides Press, Portland. 314p.

Fidalgo, O. \& Bononi, V.L.R. 1989. Técnicas de coleta, preservação e herborização de material botânico. Instituto de Botânica, São Paulo, 62p.

Gonçalves, E.G. \& Lorenzi, H. 2011. Morfologia vegetal: organografia e dicionário ilustrado de morfologia das plantas vasculares. $2^{\text {a }}$ ed. Instituto Plantarum de Estudos da Flora, São Paulo. 512p.

Govaerts, R. 2014. In: Royal Botanical Garden. Disponível em <http://www.kew.org/wcsp/monocots>. Acesso em 17 fevereiro 2014.

Hatschbach, G.G. \& Ziller, S.R. 1995. Lista vermelha de plantas ameaçadas de extinção no estado do Paraná. SEMA/GTZ, Curitiba. 139p.

Hijmans, R.J.; Guarino, L.; Bussink, C.; Mathur, P.; Cruz, M.; Barrentes, I. \& Rojas, E. 2012. DIVA-GIS: A geographic information system for the analysis of species distribution data. Versão 7.5. Disponível em $<$ http://www.diva-gis.org $>$. Acesso em 8 outubro 2013. Systematic Botany 35: 476-486.

Hoehne, F.C. 1951. Orchidaceas: Galeandra. Relatório, Comissão de linhas telegráficas e estratégicas de Mato Grosso ao Amazonas, de 1908 até 1923, Secretaria da Agricultura, São Paulo. Pp. 174-175.

Instituto Brasileiro de Geografia e Estatística (IBGE). 2012. Manual Técnico da Vegetação Brasileira. Manuais Técnicos em Geociências, n.1. Departamento de Recursos Naturais e Estudos Ambientais, Rio de Janeiro. 92p.

International Union for Conservation of Nature (IUCN). 2014. The IUCN Red List of Threatened Species. Version 2014.3. Disponível em <http://www. iucnredlist.org >. Acesso em 17 novembro 2014.

Maack R. 1968. As zonas das paisagens naturais. In: Maack, R. Geografia física do Paraná. BADEP, UFPR, Curitiba. 526p.

Monteiro, S.H.N. 2007. Revisão taxonômica e filogenia do gênero Galeandra Lindl. (Catasetinae: Orchidaceae). Universidade Estadual de Feira de Santana, Feira de Santana. 178p.

Monteiro, S.H.N.; Silva, M.F.F. \& Secco, R.S. 2009. O gênero Galeandra (Orchidaceae) na Amazônia Brasileira. Acta Amazonica 39: 21-24.

Monteiro, S.H.N.; Selbach-Schnadelbach, A.; Oliveira R.P. \& van den Berg, C. 2010. Molecular phylogenetic of Galeandra (Orchidaceae: Catasetinae) based on plastid and nuclear DNA sequences. Systematic Botany 35: 476-486.

Pabst, G.F.J. \& Dungs, F. 1975. Orchidaceae Brasilienses. I. Brucke-Verlag Schmersow, Hildesheim. 408p.

Pridgeon, A.M.; Cribb, P.J.; Chase, M.W. \& Rasmussen, F.N. 2009. Genera Orchidacearum. Vol. 5. Epidendroideae. Oxford University Press, Oxford. $585 \mathrm{p}$.

Roderjan, C.V.; Galvão, F.; Kuniyoshi, Y.S. \& Hatschbach, G. 2002. As unidades fitogeográficas do estado do Paraná. Ciência \& Ambiente 24: 75-92.

Stearn, W.T. 2004. Botanical latin. Timber Press, Portland. 546p.

Thiers, B. [continuously updated]. Index Herbariorum: A global directory of public herbaria and associated staff. New York Botanical Garden's Virtual Herbarium. Disponível em < http://sweetgum.nybg. org/ih/>. Acesso em 21 fevereiro 2014. 